\title{
Innovative surface engineering of high carbon steel through formation of ceramic surface and diffused subsurface hybrid layering
}

\author{
Rumana Hossain*a, Farshid Pahlevani**a, Sagar T Cholake ${ }^{\mathrm{a}}$, Karen Privat ${ }^{\mathrm{b}}$, Veena Sahajwalla ${ }^{\mathrm{a}}$ \\ ${ }^{a}$ Centre for Sustainable Materials Research and Technology (SMaRT@UNSW), School of Materials Science \\ and Engineering, UNSW Sydney. \\ ${ }^{b}$ Electron Microscopy Unit, Mark Wainwright Analytical Centre, UNSW Sydney \\ * Corresponding Authors: E-mail address: r.hossain@unsw.edu.au \\ ** Corresponding Authors: E-mail address:.f.pahlevani@unsw.edu.au
}

\section{Supporting information}

Table s1. Chemical composition of the investigated high carbon steel.

\begin{tabular}{|l|l|l|l|l|l|l|l|}
\hline Elements & $\mathrm{C}$ & $\mathrm{Si}$ & $\mathrm{Mn}$ & $\mathrm{Cr}$ & $\mathrm{Ni}$ & $\mathrm{Cu}$ & $\mathrm{Mo}$ \\
\hline $\mathrm{wt} \%$ & 0.99 & 0.23 & 0.98 & 0.65 & 0.06 & 0.18 & 0.02 \\
\hline
\end{tabular}

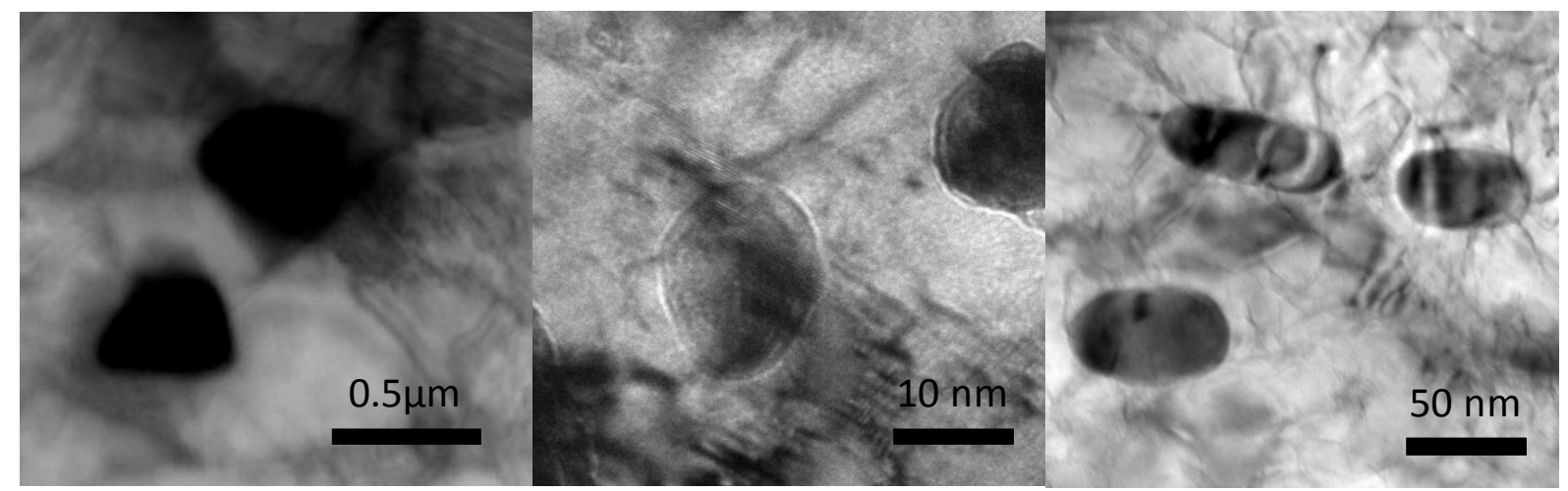

Figure s1. Bright-field High-Resolution TEM images of carbides in the diffusion zone. 